\title{
Experimental Evidence for the Effects of Organizational Culture on Managers' IT Capital Expenditure Decisions
}

\author{
John Tan \\ California State University, East Bay \\ Dongliang Lei \\ William Paterson University
}

\begin{abstract}
The research question addressed in this study is whether, in the context of an information technology investment decision, a manager will decide differently in a situation where there is no information about a firm's organizational culture compared with a situation where the firm's organizational culture is known to be either bureaucratic or innovative. This paper's experimental results show that a person will decide differently in response to knowledge of the firm's organizational culture. Results also show that for the same types of organizational culture there are no significant differences in investment decisions among participants classified as being provincial, transnational, or foreign. Additional analysis shows that personal risk profile is a significant covariate for the group of participants classified as provincials but has no effect on decision-making for participants classified as foreigners and transnationals.
\end{abstract}

Keywords: organizational culture, bureaucratic, innovative, personal risk profile, provincial

\section{INTRODUCTION}

Organizational culture is defined as a set of underlying beliefs, values, and assumptions shared by members of an organization (Schein, 1985). These underlying values influence the behavior of organizational members because employees rely on them to guide their decisions and behaviors (Schein, 1985). According to Deal and Kennedy (2000), organizational culture is therefore "the way things are done around here." Organizational culture includes the organization's vision, values, norms, systems, symbols, language, assumptions, beliefs, and habits (Needle, 2004). Corporate organizations differentiate from one another by having distinct attributes of culture in terms of norms and attitudes practiced by employees (Forehand and von Gilmer, 1964). An organization has a strong corporate culture when its employees embrace the greater part of the organization's beliefs and values (Deal and Kennedy, 1982, 2000).

Organizational culture matters because decisions made without awareness of the operative culture forces may have undesirable business consequences (Schein, 1999). An organization has a weak corporate culture when there is significant diversity between personal objectives and organizational goals (Deal and Kennedy, 1982, 2000). Organizations can design training or orientation courses to facilitate employees' assimilation into the organizational culture. In projects involving employees with different ethnic background and risk preference, such training/orientation programs can reinforce the prevailing organizational culture and encourage team members to work toward a common goal. 
Organizational culture has been extensively studied within the management discipline. For example, Wallach (1983) finds that a good fit between an individual's characteristics and the organization's culture would lead to higher productivity. However, Chatman and O'Reilly (2016) suggest that "In spite of the importance of organizational culture, scholarly advances in our understanding of the construct appear to have stagnated." Chatman and O'Reilly (2016) propose that "future research should focus on conceptualizing and assessing organizational culture as the norms that characterize a group or organization that if widely shared and strongly held, act as a social control system to shape members' attitudes and behaviors."

There is also a lack of prior studies within the management discipline or information systems discipline that studied the effects of organizational culture, ethnic background, or personal risk preference upon decision-making at the same time. This paper is an attempt to study the effects of organizational culture, personal ethnic background, and personal risk preference, but without the influence of prospect theory upon an individual's decision regarding a risky information technology investment. This paper holds constant the gain/loss of the investment outcome in order to study the effect of organizational culture on individuals' decisions.

The research question addressed in this study is whether, in the context of an information technology investment decision, a manager will decide differently in a situation where there is no information about a firm's organizational culture compared with a situation where the firm's organizational culture is known to be either bureaucratic or innovative. It is important to investigate whether a manager will change his or her decision in response to the prevailing organizational culture because of uncertainty surrounding the potential influences of the manager's personal risk preference and ethnic background on the decisionmaking process. Holding constant the gain or loss on the investment decision, subjects were asked to indicate their recommendation regarding whether the organization should invest in a multi-million-dollar integrated information technology investment project. With personal ethnical background and personal risk profile as covariates, subjects' knowledge of organizational culture was manipulated within-subjects at three levels: no knowledge of a firm's organizational culture, firm's organizational culture is known to be bureaucratic, and firm's organizational culture is known to be innovative.

Results show that a person will decide differently in response to knowledge of the firm's organizational culture. Results also show that for the same types of organizational culture, there are no significant differences in investment decisions among participants classified as being provincial, transnational, or foreign. Additional analysis shows that personal risk profile is a significant covariate for the group of subjects classified as provincials. Personal risk profile has no effect on decision-making for participants classified as foreigners and transnationals.

The main contribution of this paper to the literature is showing how organizational culture can cause a person to change their decision in the context of an information technology investment. This paper introduces the concept of "transnational" into research on the effects of personal ethnic background on decision-making.

\section{BACKGROUND AND LITERATURE REVIEW}

The existence and importance of organizational culture has been extensively described and discussed in the management literature. Academics typically define organizational culture as the basic assumptions and beliefs that are shared by members of an organization. Organizational culture is, therefore, an organization's identity, values, beliefs, attitudes, traditions, myths, norms, and accepted mode of behaviors that bind its members together consciously or unconsciously (Hood and Koberg, 1991). Organizational culture can become so dominant that it creates recognized and accepted premises for decision-making (Attwood, 1990).

Before demonstrating the reason why it is important to study the shift of employees' decisions in response to organizational culture, it is beneficial to illustrate how organizational culture can be operationalized. Organizational culture can be operationalized as a construct along distinct, repeatable dimensions (Lee and $\mathrm{Yu}, 2004$ ). The organizational culture profile (Chatman and Jehn, 1994) employs the 
Q-sort profile comparison process to analyze 54 value statements (O'Reilly et al., 1994) that capture organizational values. This paper adopts the definitions and typology of bureaucratic, innovative, and supportive organizational cultures from prior literature (Wallach, 1983). A bureaucratic culture would mean the organization is highly regulated and the information flow is based on control and power. An innovative culture would mean the organization is risk-taking, encouraging creativity within a high-pressure working environment. A supportive culture would mean an organization that stresses harmony, collaboration, and openness (Hood and Koberg, 1991).

Wallach (1983) emphasizes the importance of fit between an individual's characteristics and the organization's culture. A good fit would lead to higher productivity, job satisfaction, and commitment to remain with the organization. It is difficult for an organization to hire employees with the right fit and individuals have difficulty in locating an employer whose culture matches their characteristics.

Within the information systems discipline, researchers have studied factors such as how risk preference and prospect theory affect managers' information technology investment decisions (Rose, Rose, and Norman 2004). Frequently, there is a mismatch between organizational culture and personal characteristics regarding risk preference. It is in the context of such mismatches that the research question addressed in this study assumes importance: will a manager make a different information technology investment decision in response to knowledge of the firm's organizational culture? If a manager will change from being a risk avoider (seeker) to becoming more (less) risk-taking under an innovative (bureaucratic) organizational culture, then organizations can employ training courses to reduce the extent of mismatch between the organization's culture and employees' personal risk characteristics.

Organizational culture remains stable despite changes in leadership of the organization coupled with environmental forces that are pushing for change in the organization's culture (Campbell, 2004). In the long run, organizational culture is so important that it can be one of the decisive factors for the survival of the organization (Hofstede, 1998). A hostile culture is one of the reasons cited for failure in health care information systems implementation (Lorenzi and Riley 2000).

Lau and Hebert (2001) studied 50 information technology implementation projects reported to the annual conference of Canada's Health Informatics Association for the period 1991-1997. Lau and Hebert (2001) confirm prior findings that the key factors for successful implementation of information technology projects include the recognition that people and organizational issues are equally if not more important than the technology itself when implementing information systems (Lorenzi et al., 1997). This finding again demonstrates the importance of and the need to investigate the research question posed in this paper.

It is common for information technology implementation teams and audit teams in the "Big Four" CPA firms to have members of different ethnic backgrounds. By understanding the fit between organizational culture and ethnic culture, team leaders can build a more harmonious environment to accommodate each member's distinctive behavior while upholding the organizational culture or the accepted behavioral norms. Hofstede's model of cultural differences can be used to study whether ethnic background plays a role in an individual's decision to modify his decision regarding investing in an information technology project.

Hofstede's five forces of cultural differences are: 1) individualism versus collectivism, 2) large versus small power distance, 3) strong versus weak uncertainty avoidance, 4) masculinity versus feminity, and 5) short-term versus long-term orientation (Hostede, 2001). This study investigates whether individuals from ethnic backgrounds characterized by high power distance (collectivism) are more likely to shift their original decision, without regard to the firm's organizational culture, compared with individuals from lower power (high individualism) ethnic backgrounds.

Instead of narrowly defining ethnic background into foreigners and non-foreigners, this paper studies ethnic background in a broader sense, identifying the following ethnic groups: provincials, transnationals, and foreigners. This paper defines provincials as locals who have not traveled outside the United States (other than Canada and Mexico) or worked overseas before, and do not speak a foreign language. Foreigners are born in and have pre-college education in a foreign country, and speak a foreign language. Transnationals are locals who satisfy two of the following four conditions: speak a foreign language, have worked overseas for longer than one year, have received pre-college education in a foreign country, and/or have traveled overseas outside of the United States to countries other than Canada or Mexico. Multi- 
national corporations, like the Big Four CPA firms, or cross-border information technology projects will have members that are transnational rather than just foreigners or locals.

The other personal characteristic that this study considers is risk preference. Researchers have discovered the relevance of prospect theory and personal risk profile to the evaluation of information technology investment decisions (Rose et al., 2004). A person who is a risk seeker will decide to invest in risky information technology projects more often than will a risk avoider. Prior studies have suggested possible explanations for the differences in risk-taking behavior between risk seekers and risk avoiders. People who have suffered losses in the past will take more risk than they normally would. People who have accumulated gains in the past will avoid risk to keep their gains (Tversky and Kahneman, 1981).

It is important to study personal risk preference along with organizational culture because an innovative organizational culture would mean the organization is risk-taking, whereas a bureaucratic organizational culture would mean the organization is risk-avoiding. Manipulating organizational culture and measuring personal risk preference will facilitate determination of whether an innovative (bureaucratic) organizational culture can change the decision-making of a risk avoider (seeker). This paper holds constant the gain/loss of the investment outcome in order to study the effect of organizational culture, ethnic culture, and risk characteristics on individuals' decisions.

\section{THEORY AND HYPOTHESES}

Social identification is the perception of belonging to some human aggregate (Ashforth and Mael, 1989). An individual most probably will identify him- or herself with the organization culture of the firm for which they work. Through social identification, he or she perceives themselves as psychologically intertwined with the fate of the group, as sharing a common destiny, and experiencing its successes and failures (Tolman, 1943). Identification allows an individual to achieve accomplishments beyond his or her perceived limitations (Katz and Kahn, 1978).

It is normal for an individual to take some time to understand and adjust to the organizational culture of the firm he or she has just joined. Assume that an individual has just joined an organization and is invited to make a decision about whether to invest in an information technology project. Without the knowledge of the prevailing organizational culture, this individual will rely on available quantifiable variables of the information technology project in making the decision regarding whether to invest in the project. This individual's decision will be most influenced by his or her own personal ethnic background and risk preference.

Social Identification Theory suggests that a person will identify themselves as part of the organization with which they work (Tajfel, 1982). Through social identification, a person shares the common beliefs of the organization. Thus, per Social Identification Theory, the individual in the situation discussed above may change their original decision about whether to invest in the information technology project in light of new information about the organization culture, namely, that the organizational culture is either bureaucratic or innovative. The first hypothesis of this paper is as follows:

\section{H1: Corporate culture will change a manager's decision with respect to investing in an information technology project.}

Personal risk preference is employed as a covariate in this study while holding the gain or loss of the investment project constant. It is well established that individuals have different risk profiles--they are either risk takers or risk avoiders. Risk preference is employed as a covariate to assess the effect of organizational culture on the individual's decision-making. Prior studies have found that prospect theory interacts with an individual's risk preference in affecting their decisions in the context of information technology investments (Rose et al., 2004). Holding the gain or loss on the investment project constant allows the effect of organizational culture to be investigated without regard to the prospect theory contexts of "gain domain" versus "loss domain" decision-making. 
Hofstede's five cultural forces predict differences in behavior between individuals of different ethnic backgrounds. This paper also assumes that individuals with different ethnic backgrounds will behave differently when making decisions about an information-technology investment project. Three ethnic groups are identified in this study: provincials, transnationals, and foreigners. The second hypothesis of this paper is as follows:

H2: Personal ethnic background plays a significant role in changing a manager's decision with regard to investing in an information technology project.

\section{METHOD}

To test for the effects of organizational culture on an individual's decision-making in the context of an information technology investment, individual personal ethnical and risk characteristics are measured and used as covariates. The investment outcome of the risky information technology investment project is set to be neutral, with equal chance of gain and loss and with equal variances. The research hypotheses are tested using a one-way design.

The independent variable, organizational culture, is manipulated within subjects at three levels: no knowledge of organizational culture, knowledge of the organizational culture as bureaucratic, and knowledge of the organizational culture as innovative. Personal risk profile is measured and used as a covariate. Ethnicity is measured as provincials, transnationals, or foreigners and is also used as a covariate.

The dependent variable is the probability of investing in an information technology project and is expressed as a percentage ranging from $0 \%$ (very unlikely) to $100 \%$ (very likely). Participants are asked to circle a percentage to indicate their decision regarding investing in an information technology project under three treatments: without knowledge of organizational culture, with knowledge of a bureaucratic culture, and with knowledge of an innovative culture. To balance the study design, participants were randomly assigned to the order in which they received this information.

Individual risk preference is measured by using a lottery problem (Kim, 1992). Participants are asked to indicate their willingness to play a lottery game involving a choice between a 0.50 chance of winning $\$ 10$ and a 0.50 chance of losing $\$ 10$; responses are indicated on a Likert scale ranging from one (extremely willing) to nine (extremely unwilling).

Ethnicity is measured by a dummy variable of 0 if participants are transnationals, 1 if participants are foreigners, and 2 if participants are provincials. After they complete the experimental tasks, participants are asked about their place of birth, place of pre-college education, place of college education, overseas work experience, countries travelled to, and ability to speak foreign languages. Foreigners are foreign-born, have foreign pre-college education and speak a foreign language. Provincials are locally born, have local precollege education, have not travelled overseas (except Canada and Mexico), have not worked overseas, and do not speak a foreign language. Transnationals are locals who satisfy two of the following four conditions: pre-college education in foreign country, have travelled overseas, have worked overseas, and speak a foreign language.

Participants performed a series of tasks in a paper-based experimental session that lasted for approximately 45 minutes. All participants first reviewed a case without any information about the organization's culture. The case describes a situation wherein the largest hospital in Oahu, Hawaii, is considering a multi-million-dollar information technology investment project. Different departments within the hospital are currently operating separately without integration. When evaluated with the help of a decision aid, the multi-million-dollar information technology investment project is expected to have an equal chance of a gain or loss. Gain or loss is defined as total failure, delay, and overrun of costs. That means there is an equal chance that the project can be a total failure or a total success.

The case asks participants to assume they have just joined the hospital as assistant controller and their most previous employer was a Big Four CPA firm. Participants are asked to make decision whether to invest in the information technology project. 
Information about the organizational culture of the firm, as either bureaucratic or innovative, was then provided to the participants and the participants were asked to reevaluate their original decision about the information technology project investment in light of the organization's culture. This decision reevaluation is repeated within the remaining treatment. Participants also answered questions about their risk characteristics and exposure to foreign cultures. There was no deception involved.

Participants were randomly assigned to the condition of without knowledge of organizational culture, then with knowledge of bureaucratic (innovative), and finally, with knowledge of innovative (bureaucratic) organizational culture. Other than the order of presenting three types of organizational cultures, all participants are exposed to the same experiment content and material. After completing the task of making a decision whether to invest in the same information technology project three times, participants completed a lottery gamble survey and provided ethnic background information. Finally, participants completed simple manipulation checks. This study received Institutional Review Board approval for conducting the experiment, which was pilot-tested with PhD students.

\section{RESULTS}

\section{Full Sample Within-Subjects Analysis}

One hundred thirty undergraduate business students at a large metropolitan university in the southeastern U.S. participated in the experiment. Three participants did not complete all the questionnaires and are dropped from the data. Table 1 reports that the means of probability of investing in an information technology project are statistically significant under all three treatments. The mean for treatment of no organizational culture is 64.88189 , whereas the mean for bureaucratic organizational culture is 58.50394 . The mean of innovative organizational culture is the highest at 72.36622 .

TABLE 1

PROBABILITY OF INVESTING IN AN IT PROJECT IN EACH CULTURE CONDITION

\begin{tabular}{lllllll}
\hline Variable & $\mathbf{N}$ & Mean & Pr $>\mathbf{t}$ & Std dev & Median & Range \\
\hline No culture & 127 & 64.88189 & $<.0001$ & 22.95151 & 70 & $0-100$ \\
Bureaucratic & 127 & 58.50394 & $<.0001$ & 25.97553 & 60 & $0-100$ \\
Innovative & 127 & 72.3622 & $<.0001$ & 24.08506 & 80 & $10-100$ \\
\hline
\end{tabular}

Table 1 shows the means of probability of investing in an IT project.

Using a nine-point Likert scale with 9 as the most unwilling to play the lottery game, the mean risk profile of the 127 participants is 5.48031. The mean risk profile of 5.48031 is slightly above the median of 5 , which coincides with the assumption that students are conservative by nature. The ethnic background of the 127 participants is as follows: 22 participants are foreigners, 21 participants are transnationals, and 84 participants are provincials.

ANCOVA analysis shows that both ethnicity and risk profile are not significant as covariates. ANCOVA within subjects' pairwise comparisons show that mean differences between each of the three treatment levels are all significant at the .05 level.

Table 2 shows that the mean difference between without knowledge of culture and with knowledge of bureaucratic culture is significant (Pr .011), the mean difference between with knowledge of bureaucratic and innovative culture is significant $(\operatorname{Pr} .000)$, and the mean difference between without knowledge of culture and with knowledge of innovative culture is significant ( $\operatorname{Pr} .001)$. Results show that for each of the three treatment levels, participants did decide differently on whether to invest in the same information technology project. Analysis on the order of treatments randomly assigned to participants - control and rotating the order of bureaucratic or innovative - is found to be insignificant. The order of treatments had no effect on the results. 
TABLE 2

BONFERRONI MULTIPLE COMPARISON OF MEANS OF 127 PARTICIPANTS

\section{Pairwise Comparison}

Adjustment for Multiple Comparisons: Bonferroni

\begin{tabular}{lllc}
\hline Treatment & Number & Number & Mean Difference \\
\hline Control (no culture) & 1 & $1-2$ & $6.693(\operatorname{Pr} .011)$ \\
Bureaucratic & 2 & $2-3$ & $-14.173(\operatorname{Pr} .000)$ \\
Innovative & 3 & $1-3$ & $-7.480(\operatorname{Pr} .001)$ \\
\hline
\end{tabular}

Table 2 shows the mean difference between with and without knowledge of culture.

\section{Within-Group Analysis}

After coding participants' responses to ethnic background questions, participants are assigned to one of three groups: provincial, transnational, or foreigner. Table 3 shows that the foreigners and provincial groups are conservative with the mean risk of 6.2272 and 5.57142, respectively. With a mean risk of 4.3333, participants in the transnational group are risk takers.

Separate ANCOVA analysis for each group shows that personal risk profile is not a significant covariate for the group of subjects classified as transnational or foreigner but is a significant covariate for the group of subjects classified as provincial (Pr .026). When all 127 subjects are considered, risk is not a significant covariate.

TABLE 3

PROBABILITY OF INVESTING BY ETHNIC GROUP

\begin{tabular}{lllllll}
\hline Provincials & $\mathbf{N}$ & Mean & Pr $>\mathbf{t}$ & Std dev & Median & Range \\
\hline No culture & 84 & 63.80952 & $<.0001$ & 22.6500 & 70 & $0-100$ \\
Bureaucratic & 84 & 58.92857 & $<.0001$ & 27.0660 & 65 & $0-100$ \\
Innovative & 84 & 71.19048 & $<.0001$ & 24.1184 & 80 & $10-100$ \\
Risk & 84 & 5.57142 & $<.0001$ & 2.2843 & 5.5 & $1-9$ \\
\hline Transnational & $\mathbf{N}$ & Mean & Pr $>\mathbf{t}$ & Std dev & Median & Range \\
\hline No culture & 21 & 60.95238 & $<.0001$ & 24.0634 & 60 & $20-100$ \\
Bureaucratic & 21 & 50.95238 & $<.0001$ & 22.1144 & 50 & $20-100$ \\
Innovative & 21 & 68.57142 & $<.0001$ & 25.5510 & 70 & $20-100$ \\
Risk & 21 & 4.33333 & $<.0001$ & 2.2070 & 4.0 & $1-9$ \\
\hline Foreigners & $\mathbf{N}$ & Mean & Pr>t & Std dev & Median & Range \\
\hline No culture & 22 & 72.7272 & $<.0001$ & 22.2928 & 80 & $20-100$ \\
Bureaucratic & 22 & 62.2727 & $<.0001$ & 23.8909 & 60 & $20-100$ \\
Innovative & 22 & 80.4545 & $<.0001$ & 21.7042 & 90 & $20-100$ \\
Risk & 22 & 6.2272 & $<.0001$ & 2.4292 & 7.0 & $1-9$ \\
\hline
\end{tabular}

Table 3 shows the personal risk profile of provincial, transnational, and foreigner groups.

For the provincials group, the within-subject pairwise comparisons in Table 4 show that the mean difference between without knowledge of culture and with knowledge of bureaucratic culture is insignificant (Pr .285), the mean difference between with knowledge of bureaucratic and innovative culture is significant ( $\operatorname{Pr} .005)$, and the mean difference between without knowledge of culture and with knowledge of innovative culture is significant $(\operatorname{Pr} .011)$. 
TABLE 4

BONFERRONI MULTIPLE COMPARISON OF MEANS OF 84 PROVINCIALS

$\begin{aligned} & \text { Pairwise Comparison } \\
& \text { Adjustment for Multiple Comparisons: Bonferroni }\end{aligned}$
\begin{tabular}{llll} 
Treatment & Number & Number & Mean Difference \\
\hline Control (no culture) & 1 & $1-2$ & $4.881(\operatorname{Pr} .285)$ \\
Bureaucratic & 2 & $2-3$ & $-12.262(\operatorname{Pr} .005)$ \\
Innovative & 3 & $1-3$ & $-7.381(\operatorname{Pr} .011)$ \\
\hline
\end{tabular}

Table 4 shows within-subject pairwise comparisons of mean differences for 84 provincials.

For the group of subjects classified as transnational, the within-subject pairwise comparisons in Table 5 show that the mean difference between without knowledge of culture and with knowledge of bureaucratic culture is insignificant $(\operatorname{Pr} .088)$, the mean difference between with knowledge of bureaucratic and innovative culture is significant ( $\operatorname{Pr} .018)$, and the mean difference between without knowledge of culture and with knowledge of innovative culture is insignificant $(\operatorname{Pr} .141)$.

\section{TABLE 5 \\ BONERRONI MULTIPLE COMPARISON OF MEANS OF 21 TRANSNATIONALS}

\begin{tabular}{llll}
\hline $\begin{array}{l}\text { Pairwise Comparison } \\
\text { Adjustment for Multiple Comparisons: Bonferroni }\end{array}$ & & & \\
\hline Treatment & Number & Number & Mean Difference \\
Control (no culture) & 1 & $1-2$ & $10.000(\operatorname{Pr} .088)$ \\
Bureaucratic & 2 & $2-3$ & $-17.619(\operatorname{Pr} .018)$ \\
Innovative & 3 & $1-3$ & $-7.619(\operatorname{Pr} .141)$ \\
\hline
\end{tabular}

Table 5 shows within-subject pairwise comparisons of mean differences for 21 transnationals.

For the group of subjects classified as foreigner, the within-subject pairwise comparisons in Table 6 show that the mean difference between without knowledge of culture and with knowledge of bureaucratic culture is insignificant $(\operatorname{Pr} .110)$, the mean difference between with knowledge of bureaucratic and innovative culture is marginally insignificant $(\operatorname{Pr} .051$ ), and the mean difference between without knowledge of culture and with knowledge of innovative culture is insignificant ( $\operatorname{Pr} .774)$.

TABLE 6

BONERRONI MULTIPLE COMPARISON OF MEANS OF 22 FOREIGNERS

$\begin{aligned} & \text { Pairwise Comparison } \\
& \text { Adjustment for Multiple Comparisons: Bonferroni }\end{aligned}$
\begin{tabular}{llll} 
Treatment & Number & Number & Mean Difference \\
\hline Control (no culture) & 1 & $1-2$ & $10.455(\operatorname{Pr} .110)$ \\
Bureaucratic & 2 & $2-3$ & $-18.182(\operatorname{Pr} .051)$ \\
Innovative & 3 & $1-3$ & $-7.727(\operatorname{Pr} .774)$ \\
\hline
\end{tabular}

Table 6 shows within-subject pairwise comparisons of mean differences for 22 foreigners.

\section{Between-Group Analysis}

Bonferroni comparison of means is used to test for differences between groups at each treatment level. By holding knowledge of organizational culture constant at each of the three levels - no knowledge of 
culture, knowledge as bureaucratic and knowledge as innovative - there is no significant difference at the .05 level between the means of provincial and foreigner, or provincial and transnational, or foreigner and transnational. This is contrary to the prediction that ethnic background will cause differences in decisionmaking.

\section{DISCUSSION AND CONCLUSION}

This study investigates whether a manager will change their decision in response to the prevailing organizational culture. Within-subject analysis of 127 participants shows significant differences between

participants' IT investment decisions, between without knowledge of culture and with knowledge of bureaucratic or innovative organizational culture, and between with knowledge of bureaucratic and innovative organizational culture. Because the results support differences at each treatment level, Hypothesis 1 is supported. The implication of this finding is that when there is a sharp contrast between two organizational cultures, such as bureaucratic versus innovative, employees may change their decision in response to the knowledge of prevailing organizational culture.

Hypothesis two is not supported. Holding culture constant at each of the three treatment levels, no knowledge of culture, knowledge as bureaucratic and knowledge as innovative, there is no difference in the means between groups of provincials and transnationals, provincials and foreigners, or foreigners and transnationals. This result, though, is contrary to prediction and should be interpreted with caution due to the unequal cell sizes: provincials have 84 participants, transnationals have 21 participants, and foreigners have 22 participants.

Within each group, the risk covariate is statistically significant for provincials but not for transnationals or foreigners. When all 127 subjects are considered, risk and ethnicity are not as significant as covariates.

The main contribution of this paper to the literature is showing how organizational culture can cause a person to change their decision in response to their knowledge of an organization's culture. This paper introduces the concept of transnationals into the research on the effects of personal ethnic background on decision-making. Future research can study the benefits of including transnationals as members of team projects instead of just focusing on foreigners. This paper has the limitations of using student subjects and holding gain or loss of the investment project constant. Student subjects are poor surrogates for managers in organizations who make information investment decisions. Another limitation of this paper is the fact that organizational culture was manipulated within subjects, which makes the treatment more salient to the participant. Future research could employ a design where organizational culture is manipulated between subjects. Future research can also incorporate the effect of prospect theory into the study of the effect of organizational culture, personal ethnic background, and risk preference.

\section{REFERENCES}

Ashforth, B.E., \& Mael, F. (1989). Social Identity Theory and the Organization. The Academy of Management Review, 14(1), 20-39 https://doi.org/10.2307/258189

Attwood, T. (1990, January). Corporate Culture: For You or Against You? Management Accounting, pp. 26-29.

Campbell, C.R. (2004). A Longitudinal Study of One Organization's Culture: Do Values Endure? American Journal of Business, 19(2), 41-52. https://doi.org/10.1108/19355181200400011

Chatman, J.A., \& Jehn, K.A. (1994). Assessing the Relationship Between Industry Characteristics and Organizational Culture: How Different Can You Be? Academy of Management Journal, 37(3), 522-553. https://doi.org/10.2307/256699

Chatman, J.A., \& O'Reilly, C.A. (2016). Paradigm lost: Reinvigorating the study of organizational culture. Research in Organizational Behavior, 36, 199-224.

https://doi.org/10.1016/j.riob.2016.11.004

Deal, T.E., \& Kennedy, A.A. (1982). Corporate Cultures: The Rites and Rituals of Corporate Life. Harmondsworth, Penguin Books, 1982; reissue Perseus Books, 2000. 
Forehand, G.A., \& Von Haller, G. (1964). Environmental variation in studies of organizational behavior. Psychological Bulletin, 62(6), 361-382. https://doi.org/10.1037/h0045960

Hofstede, G. (1980). Cultural Culture's consequences: Intelligence differences in work-related values. Beverly Hills, CA: Sage.

Hofstede, G. (1990). Cultures and organizations: Software of the mind. London: McGraw Hill.

Hofstede, G. (1998). Attitudes, Values and Organizational Culture: Disentangling the Concepts. Organization Studies, 19(3), 477-493. https://doi.org/10.1177/017084069801900305

Hofstede, G. (2001). Culture's consequences: Comparing values, behaviors, institutions, and organizations across nations. Thousand Oaks, California: Safe.

Hood, J.N., \& Koberg, C.S. (1991). Accounting Firm Cultures and Creativity Among Accountants. Accounting Horizons, 5(3), 12-19.

Katz, D., \& Kahn, R.L. (1978). The social psychology of organizations (2nd ed.). New York: Wiley.

Kim Jean Lee, S., \& Yu, K. (2004). Corporate Culture and Organizational Performance. Journal of Managerial Psychology, 19(4), 340-359. https://doi.org/10.1108/02683940410537927

Kim, D. (1992). Risk Preferences in Participative Budgeting. The Accounting Review, 67, 303-318.

Lau, F., \& Hebert, M. (2001). Experiences from Health Information System Implementation Projects Reported in Canada Between 1991 and 1997. Journal of Organizational and End User Computing, 13(4), 17-25. https://doi.org/10.4018/joeuc.2001100102

Lorenzi, N.M., \& Riley, R.T. (2000). Managing Change: An Overview. Journal of the American Medical Informatics Association, 7(2), 116-124. https://doi.org/10.1136/jamia.2000.0070116

Lorenzi, N.M., Riley, R.T., Blyth, A.J.C., Southon, G., \& Dixon, B.J. (1997). Antecedents of the People and Organizational Aspects of Medical Informatics: Review of the Literature. Journal of the American Medical Informatics Association, 4(2), 79-93. https://doi.org/10.1136/jamia.1997.0040079

Needle, D. (2004). Business in Context: An Introduction to Business and Its Environment. Cengage Learning.

O’Reilly, C.A., Chatman, J., \& Caldwell, D.F. (1991). People and Organizational Culture: A Profile Comparison Approach to Assessing Person-Organization Fit. Academy of Management Journal, 34(3), 487-516. https://doi.org/10.2307/256404

Rose, J.M., Rose, A.M., \& Norman, C.S. (2004). The Evaluation of Risky Information Technology Investment Decisions. Journal of Information Systems, 18(1), 53-66. https://doi.org/10.2308/jis.2004.18.1.53

Schein, E.H. (1985). Organizational culture and leadership. San Francisco: Josey-Bass Publishers.

Schein, E.H. (1999). The Corporate Cultural Survival Guide. San Francisco: Jossey-Bass Publishers.

Tajfel, H. (1982). Instrumentality, Identity and Social comparisons. In T.H. Cambridge (Ed.), Social Identity and Intergroup Relations. England: Cambridge University Press.

Tolman, E.C. (1943). Identification and the Postwar World. The Journal of Abnormal and Social Psychology, 38(2), 141-148. https://doi.org/10.1037/h0057497

Tversky, A., \& Kahneman, D. (1981). The Framing of Decisions and the Psychology of Choice. Science, 211(4481), 453-458. https://doi.org/10.1126/science.7455683

Wallach, J.E. (1983, February). Individuals and Organizations: The Cultural Match. Training and Development Journal, pp. 29-36. 